\title{
COMPARATIVE STUDY OF HIGH RESOLUTION SATELLITE IMAGES TO DEMARCATE GROUNDWATER POTENTIAL ZONES IN SRIPERUMBUDUR, CHENNAI
}

\author{
Shyam Sundhar.V 1 , S. Sanjeevi Prasad ${ }^{2}$ and Indrani Mukherjee ${ }^{3}$ \\ ${ }^{1}$ Research Scholar, ${ }^{2}$ Assistant Professor, ${ }^{3}$ M.Sc. Student, \\ Department of Geography, University of Madras, Chennai, India
}

\begin{abstract}
The study focuses comparison of hyperspectral and multispectral imagery for identifying the groundwater potential zones and aquifers of Sriperumbudur region. It also tries to identify which image tends to be better for groundwater analysis without ground truth verification. In present going to field and then selecting spot for digging the groundwater is tiring and time taking. The need of conservation and its resource assumes more importance than ever before. Water scarcity has always remained a problem in the city of Chennai. For conserving of water, the study attempts to mark the potential zone which is exposed for getting polluted and contributing to health risk. The various thematic maps have been prepared such as landuse pattern, soil type, geology, geomorphology and lineament were used for identifying the potential zone. Weightage and ranking were given to each parameter before overlaying all the parameters. Therefore, the study is to sort the problem of ground truth verification for identifying area, and identify the zone through remote sensing and Geographical Information System (GIS).
\end{abstract}

Key words: Groundwater Potential, Hyperion, Geographical Information System

\section{Introduction}

Groundwater resource is considered to be the most important freshwater resource. With increasing population in the metropolitan is not only threat to the reserve but also its quality. The fast growing population needs a continuous supply for freshwater. For protecting these zones, we need to find the zones and demarcate them. Hence taking Chennai as our study area which is also a metropolitan city of India as well as it faces acute water scarcity throughout the year. The groundwater potential zones are first identified and analyzed to find out the status or condition of the zones in relation with the quality and what will be health risks. To identify the groundwater potential zones, techniques of GIS and remote sensing has been used. Thematic maps like geology, soil, and lineament has been prepared to enhance the exploration of potential groundwater zones. Groundwater is presently found to be most important freshwater source. As the rising population needs supply of water therefore it has become mandatory to discover the potential zone of groundwater. A standard technology applied to predict groundwater potential zone using remote sensing and GIS techniques using various tools. Many thematic maps were created such as slope map, lineament maps etc. The most significant recent breakthrough in remote sensing has been the development of hyperspectral sensors and software to analyses the resulting image data. Fifteen years ago only spectral remote sensing experts had access to hyperspectral images or software tools to take advantage of such images. Over the past decade hyperspectral image analysis has matured into one of the most powerful and fastest growing technologies in the field of remote sensing.

\section{Methodology}

With satellite imagery of IRS-P6-LISS-IV (2013) lineament map was prepared, with same parameters layer stacking of Hyperion image was also done to analyses the advantage. When all this parameter was processed, then final overlay map with potential zone was derived. Finally, NDVI was derived to analyses the presence of aquifer in the zone. The aquifer map was compared with potential zone map to analyses the potential zone derived. 
Figure 01: Study Area Sri Perumbudur

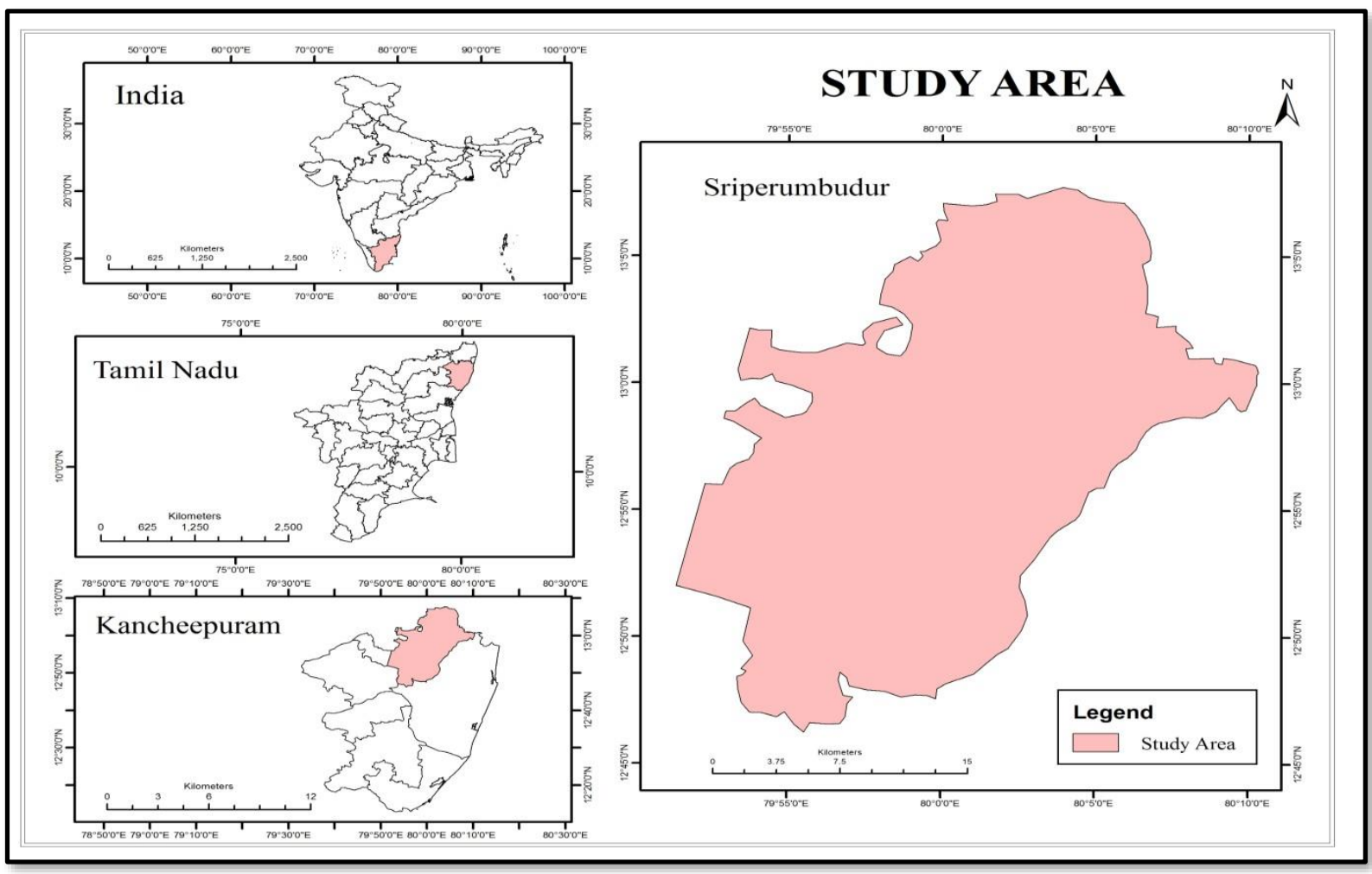

\section{Multispectral Analysis}

As we can see in the map the tree features are dominant in the study area which are: Argillaceous and calcareous sandstone and Granet-biotite-sillimanite graphite gneiss. The clay is in least quantity in the area. The sand and silt is found only in the south eastern and southern part of the study area.

Figure 02: Geology Map

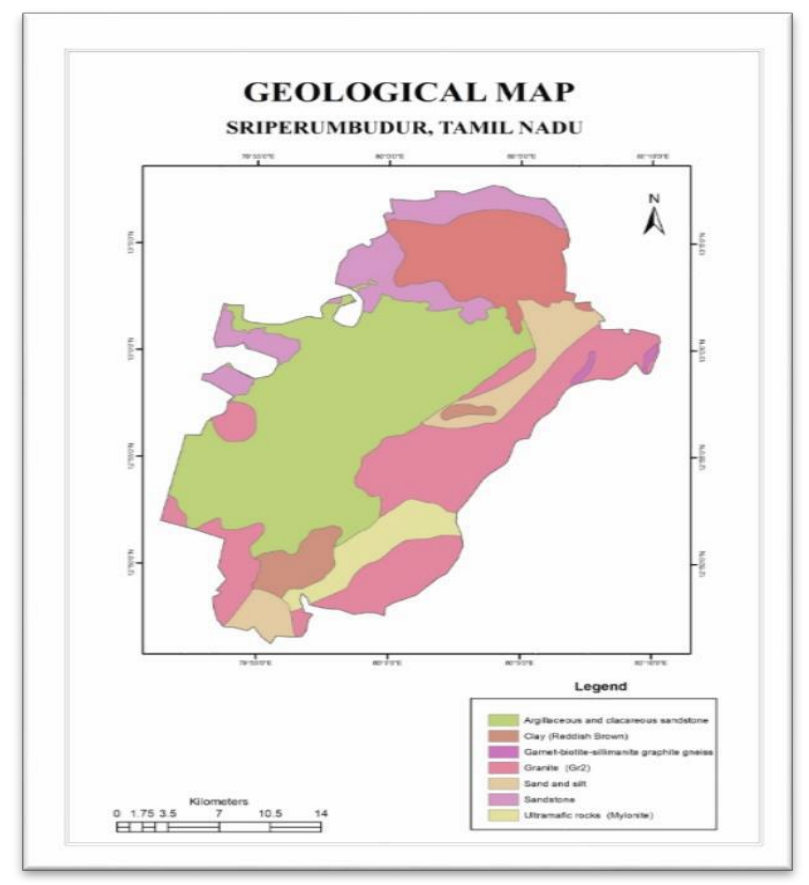

Figure 03: Soil Map

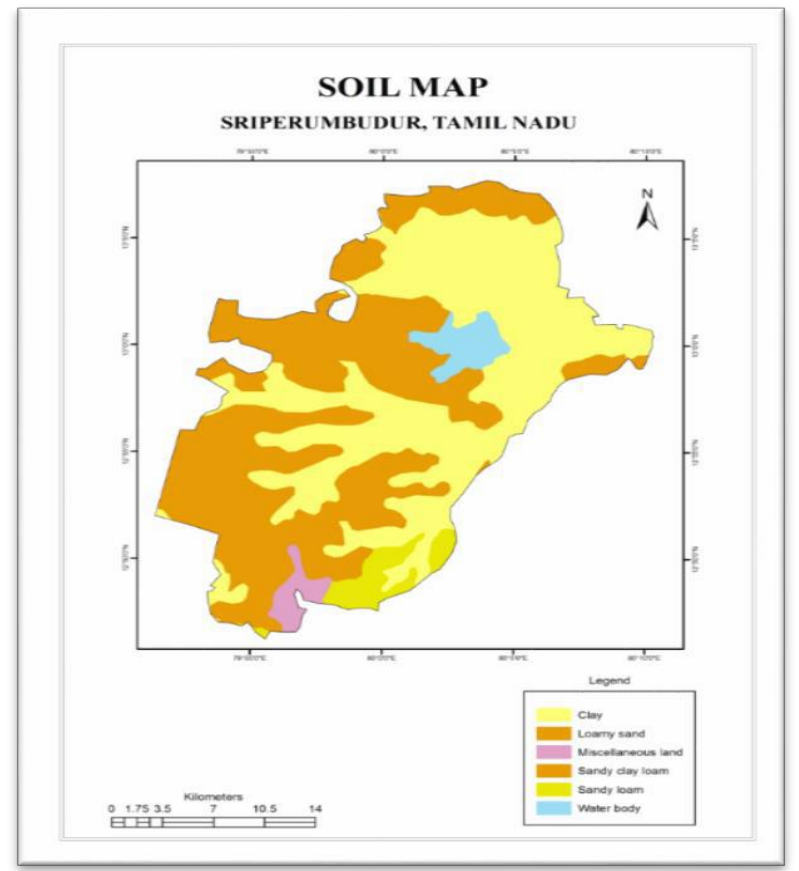

The map shows the area has 6 different types of soil which are: Clay, Clay loam, Sand, Loamy sand, Miscellaneous land, Sandy clay loam, and Sandy loam. The western part of the study area is dominated by loamy sand. The eastern part of the study area is covered by the clay soils and less part is loamy sand. The study area shows good proportion of loamy sand which helps in higher level of water penetration. 


\section{Lineament Map and Geomorphological Map}

This map shows that the maximum fractured areas in the study area are in western part. More fractured areas were found in the northern and southern part of the study area in compare to the central part of the study area. The maximum fracture lines are parallel to the eastern boundary of the study area which is also a coastal line. The western part of the area has less number of fractures in compare to the eastern part. This map shows the geomorphologic features of the study area and 4 geomorphologic features are identified in the study area which is: Alluvial Plain, Coastal Plain, Flood Plain, Pedi plain Structural hill. As we can see the coastal plain is found along the coastal line and the alluvial plain is found in the western central part of the study area, Pedi plain is found in the west northern and west southern part of the study area and the flood plain is found in a linear manner in the central part of the study area. High percolation of groundwater is found in the coastal plain and the others having low percolation capacity.

Figure 04: Geomorphological Map

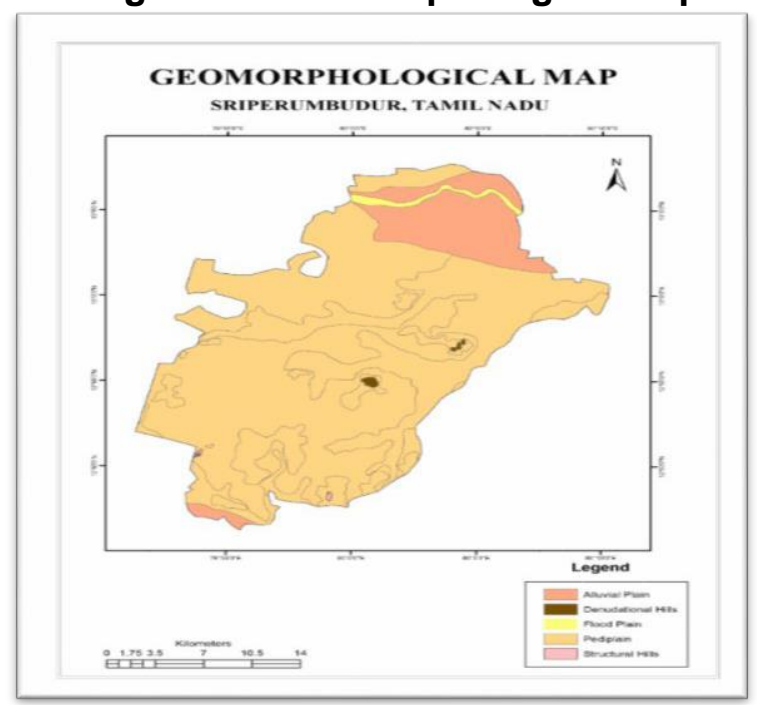

Figure 05: Lineament Map

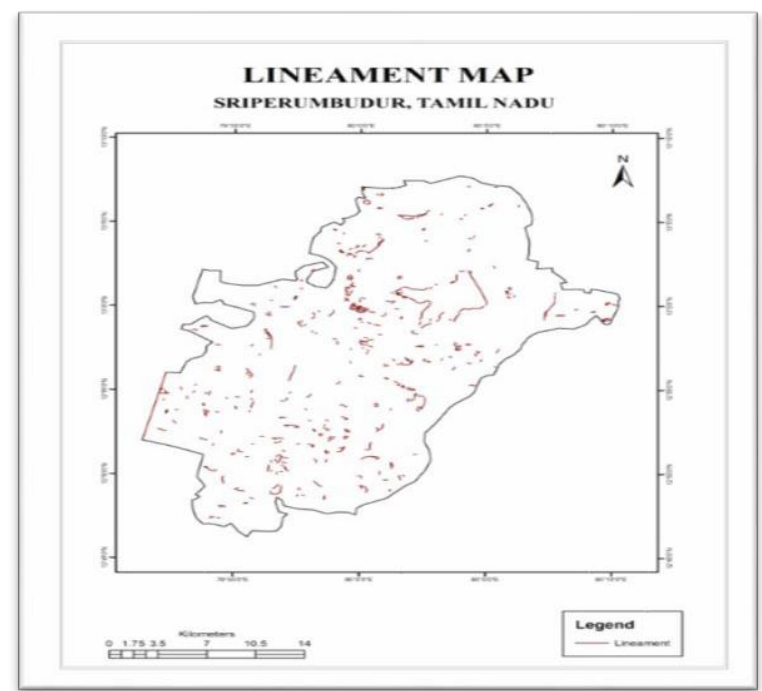

Figure 06: Land use and Land cover Map

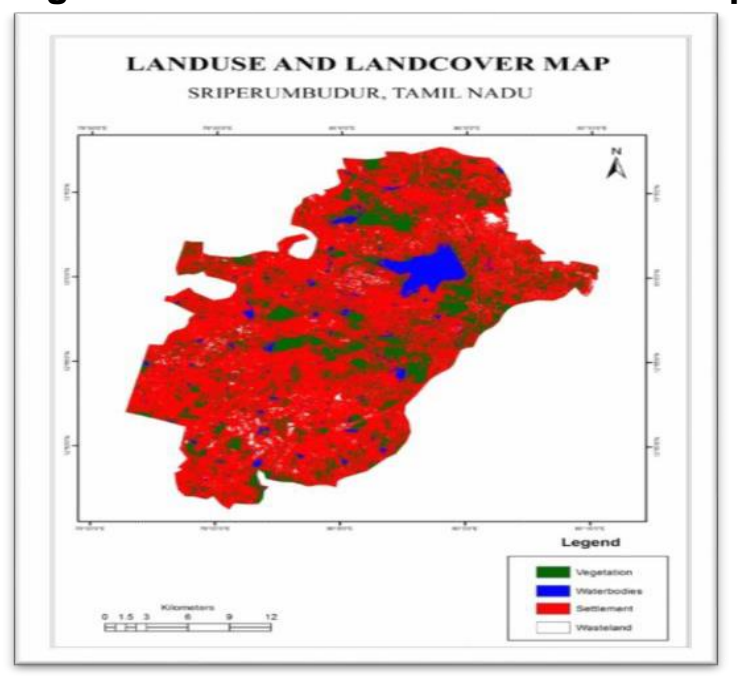

Table 01: Land use Classification in Area

\begin{tabular}{|l|c|}
\hline Land use Classification & Area (in Hectares) \\
\hline Vegetation & 15129.4 \\
\hline Water bodies & 2957.4 \\
\hline Settlement & 50087.3 \\
\hline Wasteland $\quad$ Total & 6741.0 \\
\hline \multicolumn{2}{|c|}{} \\
\hline
\end{tabular}


The map shows settlements, water bodies, vegetation and wasteland of the area. Here the water bodies are very less and the settlements are more in the area. The LULC map suggests that there is high population attraction due to satisfactory water availability.

\section{Hyperion Analysis}

Figure 08: Spectral Index Map

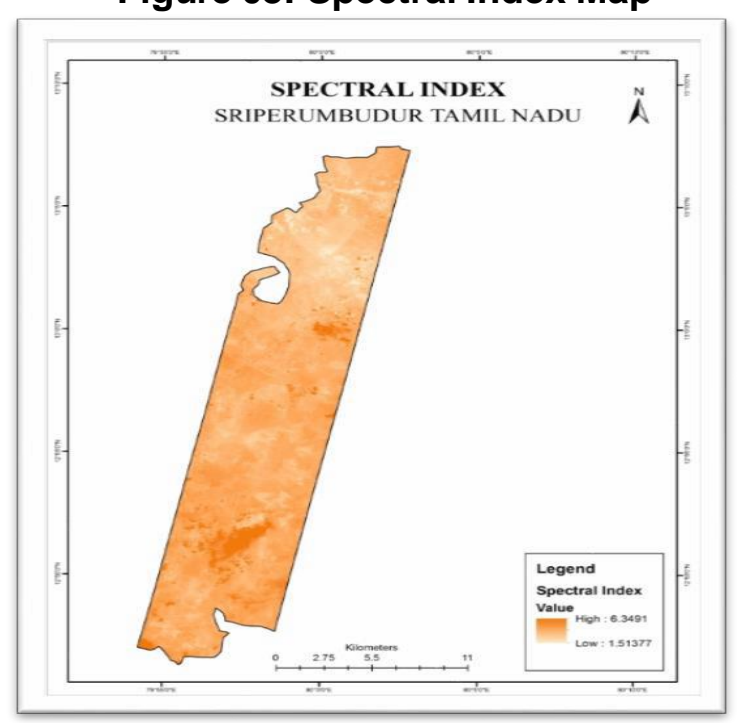

Figure 09: Layer Stacking Map

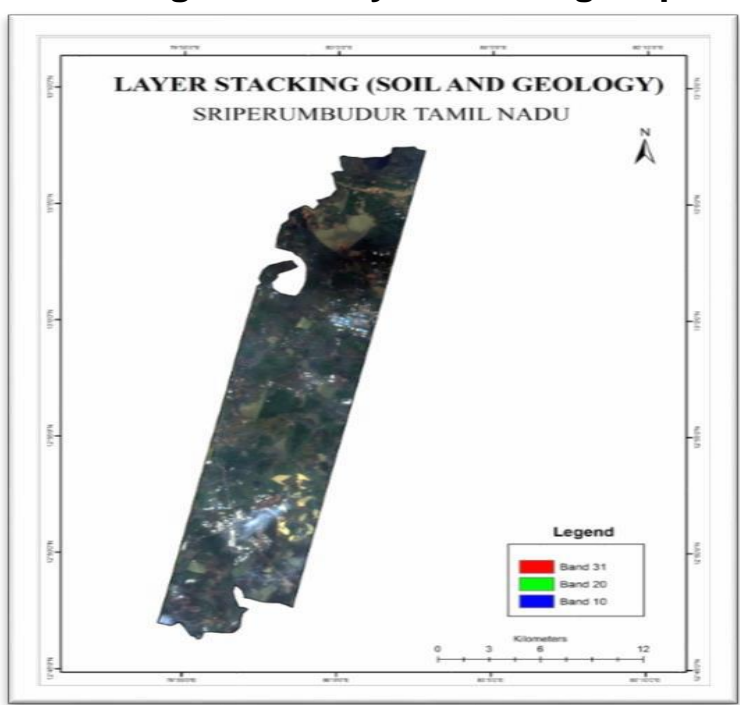

\section{Soil and Geology Map}

The layer stacking has been done using band 10, 20 and 31 for soil and geology the layer stacking helps to derive the yellow colour, which helps in identifying the various soil and rock type by deriving the spectral reflectance in the map. The soil line of the soil reflectance spectra, characterizes the soil type, defines vegetation indices, and corrects the plant canopy reflectance from the optical soil property effects. Also with same band combination and reflectance geology can be identified. Therefore, the reflectance value suggests mostly the area is covered with the clayey materials. Also granite is identified with wavelength of least reflectance value. The lesser reflectance value suggests that they have very minimum capacity of holding water for soil. This compactness, porosity and permeability characterize the area capability to penetrate water and recharge in the natural aquifer beneath.

\section{Lineament Map}

The map shows lineament distribution of the study area. The lineament shows the fractures of the land which will penetrate or allow the water to percolate into the reach water table. The lineament which is derived using band no.4 shows that the region is having high density of lineament present especially in the southern part of the covered study area. Therefore, we can estimate high penetration.

Fig 10: Lineament Map

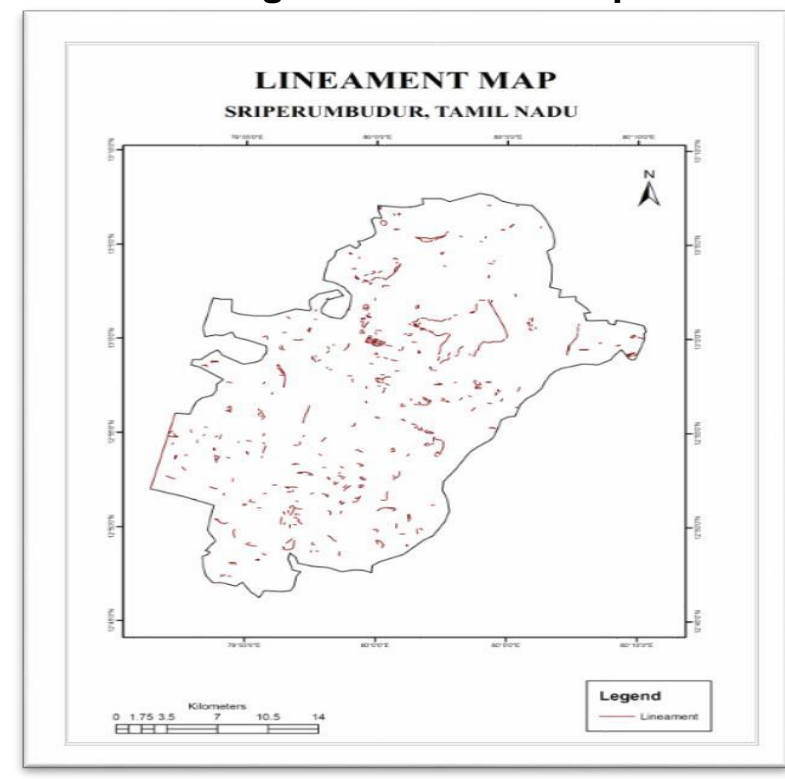

Figure 11: NDVI Map

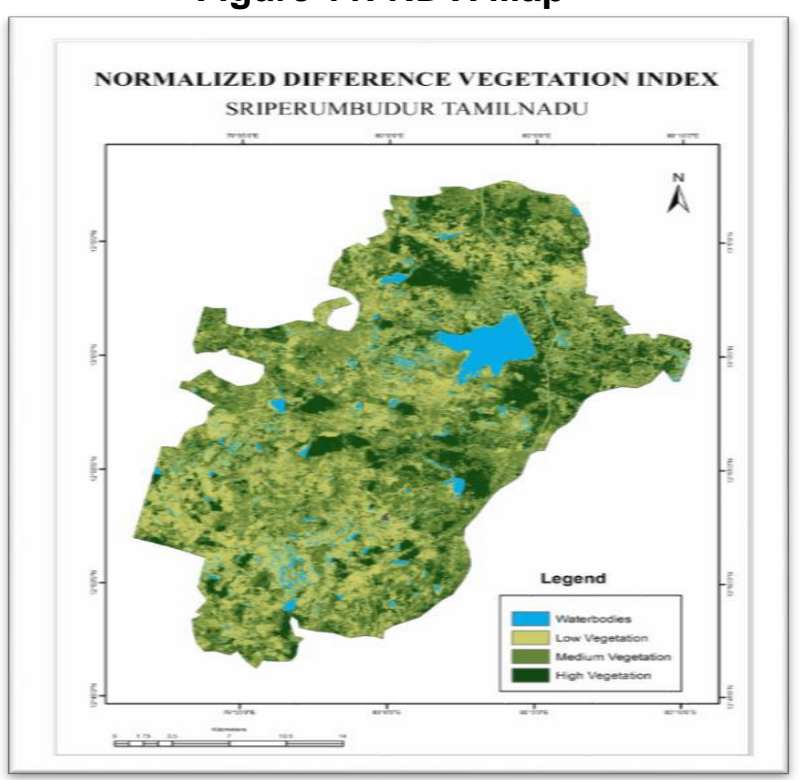




\section{Normalized Difference Vegetation Index (NDVI)}

The area basically shows coverage of medium level of vegetation coverage but also in few patches are of higher vegetation. Water body's area also identified along where higher vegetation coverage is found. The area is maximum under medium coverage of vegetation, which signifies that soil holds enough moisture for plants to grow. Also soil and geology helps to promote its growth. After analyzing of all the features from the settled parameters the maps have been overlay upon each other and with help of overlay analysis the potential zone map has been prepared. Following were the ranks and weightage to given to each map before overlaying them: With the given parameters the followed map was derived and that was divided into three different zones:
- High potential zone
- Medium potential zone
- Low potential zone

Table 02: Weightage and Ranking

\begin{tabular}{|l|l|c|}
\hline Parameters & Ranking & Weightage (\% of influence) \\
\hline Geology & 1 & 40 \\
\hline Lineament & 2 & 35 \\
\hline Geomorphology & 3 & 15 \\
\hline Soil & 4 & 10 \\
\hline
\end{tabular}

Figure 12: Potential Zone Map (LISS-IV)

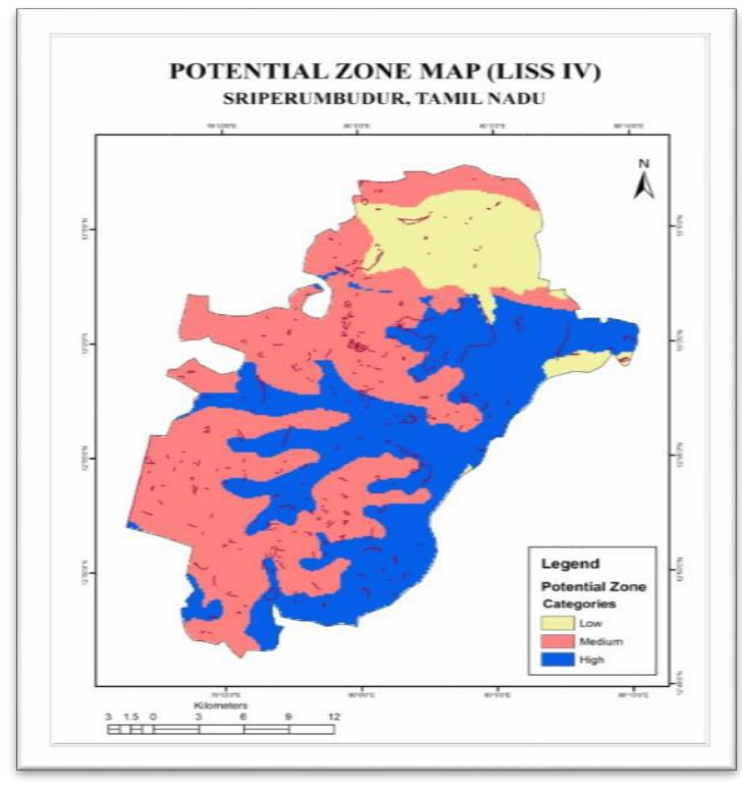

Figure 13: Potential Zone Map (HYPERION)

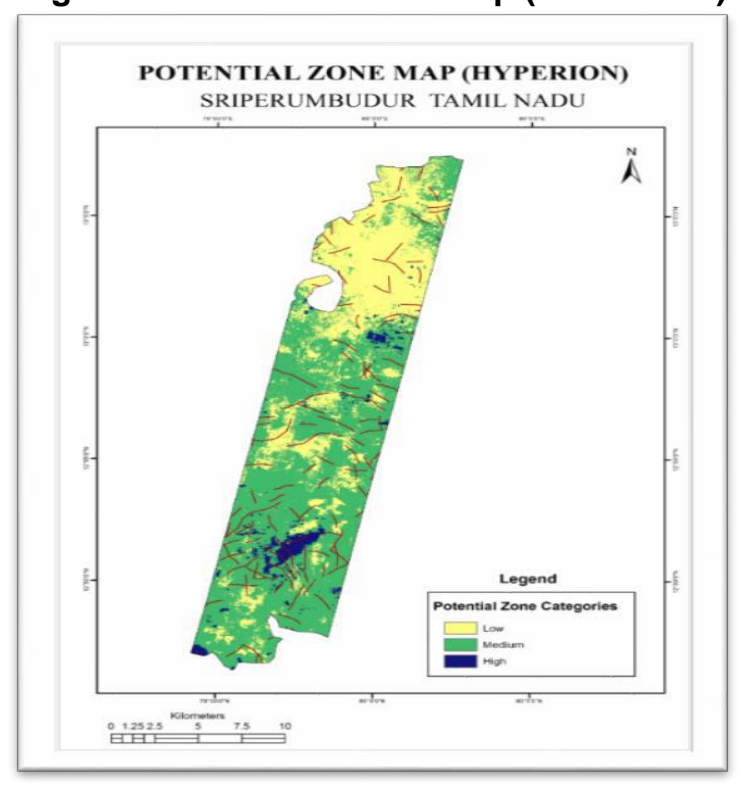

\section{Potential Groundwater Zone Map}

An overlay map has been prepared to show the possible potential zone for groundwater. The map has been divided into three zones. The zones are marked as I, II and III. The derived map suggests that the eastern part is highly potential zone with suitable geology and geomorphology combination to enhance its aquifer to recharge and store the water. The western side is basically medium potential zone and the northern zone is low potential it's a minimum area. Therefore, we can say the area is having good potential zone. So the area is having satisfactory water potential in this area. Therefore, with done analysis and available data we can say that there is aquifer present in zone. Along with information that it has satisfactory groundwater level and quality we can say that it is recharged regularly and this helps it maintain its quality and marks it to be safe.

The groundwater zone map has been prepared using Hyperion image. The rasters of soil, geology and lineament are overlaid upon each other. The map is divided into three potential zones that is high, medium and low potential water zone. The maximum zone comes under medium potential zone and the southern part is having high potential zone. But the area shows that there is good amount of lineament distribution, which shows that there is good source of water penetration to charge water table. Hence we can say that area is satisfactorily potential for groundwater. 


\section{Aquifer Map}

The principal aquifer system map has been derived from the secondary source. Here the map shows various aquifers formed over the area and is compared with the derived potential zone map. As per the principal aquifer system suggests that aquifers are mainly formed out of four type rock system. The soil and the rock promote the storage and recharge of the aquifers. The prepared map of the potential zone when compared with the aquifer map it shows that aquifers are found mainly in the areas where there is suitable combination of soil, geology, geomorphology, soil and lineament. The zone where medium and high potential zone are concentrated, there mainly aquifers are spotted in the map. Hence we can interpret that potential zone helps aquifer to develop.

Figure 14: Principal Aquifer System

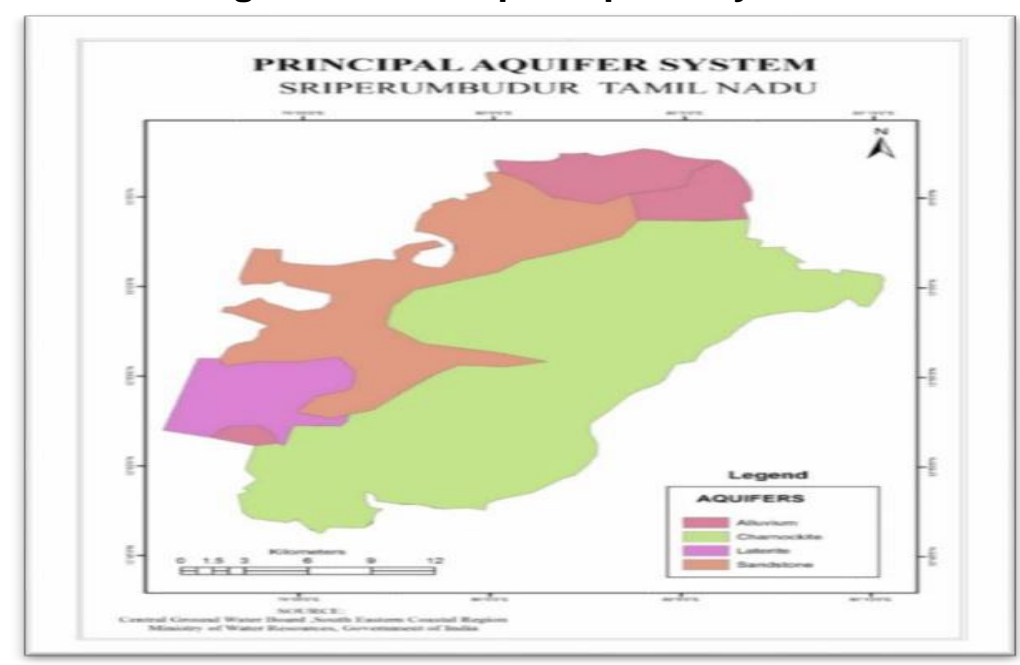

\section{Conclusion}

While working with two different sets of satellite images different features were observed while processing and analyzing: For multispectral image processing there should be satellite image as well as geochemical data to derive the overlay analysis due to lesser amount of bands whereas for hyperspectral image geochemical maps can be derived using the specific band combination. There are more than 100 bands so combination of bands can be selected as per requirement. In terms of area multispectral cover larger area in shorter temporal resolution i.e. 5 days, but hyperspectral covers lesser area in temporal resolution of 200 days. So to be keeping updated and cover larger area multispectral is more preferable. Multispectral has better spatial resolution but resolution for hyperspectral it's not so clearer since the former has $5.8 \mathrm{~m}$ and later has $30 \mathrm{~m}$ resolution.

For processing and interpreting multispectral it's easier as we derive can true colour composite easily than processing Hyperion. Through the study it has being identified that there cannot be full assurance of recharging the water table, through remote sensing analysis. As we can find out that there is maximum content of clay which signifies that there is high amount of porosity but this doesn't contribute for recharging aquifers as the specific yield tends to be negative. Hence it can be suggested that Hyperion is better for analysing potential zones as the geophysical data can be derived with the Hyperion image. Better thematic layouts can be given from the Hyperion image. As a limitation we can say that there should be ground truth verification to suggest about presence and recharge of aquifers.

\section{References}

1. Adams, John B., Smith, M.O., and Gillespie, A.R. (1993) Imaging Spectroscopy: Interpretation Based on

2. Anbazhagan S, Jothibasu A (2014) Geoinformatics in groundwater potential mapping and sustainable development: a case study from southern India. Hydrol. Sci. Journal.

3. Anuradha. C.T. and Prabhavathy S. (2010) "Water resources management for Virudhunagar District using remote sensing and GIS". International Journal of Earth Sciences and Engineering, 3(1): 55-61, Spl. issue,

4. Ashok Kumar L. and Shanmugam S. (2014) "Hyperspectral band selection and 
classification of Hyperion image of Bhitarkanika mangrove ecosystem, eastern India" Proceedings of SPIE - The International Society for Optical Engineering

5. Babu Ganesh. O and Sashikkumar M.C. (2009) Demarcation of groundwater recharge potential zones for 7(1):65-75CrossRef

6. Bagyaraj M, Ramkumar T, Venkatramanan S, Gurugnanam B (2013) Application of remote sensing and GIS

7. G.P. Thomas (2012) Hyperspectral Imaging Methods, Benefits and Applications 89-105.

8. Ganapuram Sreedhar, Vijaya Kumar. G.T, Murali Krishna I.V., Kahya Ercan Cuneyd Demirel (2009) Mapping of groundwater potential zones in the Musi basin using remote sensing data and GIS

9. Introduction to Hyperspectral Imaging (2012) TNT MIPS analysis for identifying groundwater potential zone in parts of Kodaikanal Taluk, South India. Front Earth Sci Hyperspectral Image Analysis Keonjhar (Orissa), India

10. Klemas Victor and Pieterse Aline (2010) Using Remote Sensing to Map and Monitor Water Resource in Arid and Semiarid Regions

11. Meijerink, A.M.J., Gieske, A.S.M and Vekerdy, Z., (2005) Surface energy balance using satellite data for the water balance of a traditional irrigation-wetland system in SW Iran. Irrigation and Drainage Systems, 19, pp.

12. Nag S.K. (2005) Application of lineament density and Hydro geomorphology to delineate groundwater potential zones of Baghmundi block in Purulia district, West Bengal. Journal of the Indian Society of Remote Sensing, Vol. 33, No. 4

13. Pieter's, Carle M. And Angler, Peter A.J. (eds.) (2001) Remote Geochemical Analysis: Elemental and

14. Saraf, A.K. and Chowdhury, ER. (1998) Integrated remote sensing and GIS for groundwater exploration and identification of artificial recharge sites. International J. of Remote Sensing, 19(10): 1825-1841.

15. Sekhar Ashok (2001) Mineral abundance mapping using hyperion dataset in parts of Udaipur (Rajasthan) and

16. Selvam. G, Banukumar.K, Srinivasan.D, Selvakumar.R and Alaguraja.P. (2011) Identification of groundwater potential zone in hard rock terrain - A case study from parts of Manapparai block Tamilnadu using Remote Sensing and GIS techniques International Journal of Advances in Remote Sensing and GIS

17. Srinivasa Rao, Y., Reddy, T.V.K. and Nayudu, P.T. (2000) Groundwater targeting in a hard rock terrain using fracture- pattern modeling, Niva River Basin, Andhra Pradesh, India. Hydrogeology Journal, Vol. 8, pp. 494. 